\title{
Research on Management Cost Control Based on Financial Sharing Model
}

\author{
Cai Zhixing \\ Hangzhou College of Commerce, Zhejiang Gongshang University, Hangzhou, China
}

\section{Email address:}

niezhi798287@163.com

\section{To cite this article:}

Cai Zhixing. Research on Management Cost Control Based on Financial Sharing Model. Science Innovation. Vol. 5, No. 6, 2017, pp. 381-385. doi: $10.11648 /$ j.si.20170506.19

Received: October 23, 2017; Accepted: October 31, 2017; Published: December 6, 2017

\begin{abstract}
At present, with the development of global economic integration, enterprises in the process of growth and development, has been to limit and control costs, operation efficiency, and lack of ability to control factors. In order to develop the enterprise scale, promote cost savings, improve operational efficiency, and improve or problems to restrict the development process to solve the enterprise, stripping and integration gradually the non core business of many enterprises, and gradually the main energy and resources, into the core business, which also makes the financial shared mode came into being. In this new sharing model, many international financial institutions or institutions have set up their service center for Financial Sharing mode. And how to determine the advantages of the financial sharing model, as well as its mature model, for the current stage of enterprise cost control, is tantamount to great practical significance. In this regard, this paper first describes the financial shared enterprise management mode and the traditional mode under different; then based on the conclusion and outstanding research results of previous studies, the cost of enterprise management are defined and classified in detail, the management cost is divided to internal cost and external transaction cost, opportunity cost, agency cost three categories and the characteristics of all kinds of management and cost accounting model are introduced and summarized, according to the constitution of management cost behavior and description, combining with the characteristics of the mode of financial sharing, on the two aspects of management cost accounting in formation and are controlled respectively optimization research. And then it concludes: cost management as an important part of the enterprise comprehensive cost, not only the need for the implementation of financial shared mode, must constantly improve the optimization work, cost control management and constitute the only way that can promote the sustainable development of enterprises in the road steadily.
\end{abstract}

Keywords: Financial Sharing Model, Management Costs, Behavior and Composition, Formation and Accounting

\section{基于财务共享模式的管理成本控制研究}

\section{蔡智星}

杭州商学院, 浙江工商大学, 杭州, 中国

邮箱

niezhi798287@163.com

摘要：当前，随着全球经济一体化模式的不断推进，促使企业在成长与发展过程中，不断受到成本上升、运营效率降 低、以及管控能力不足等方面因素的限定与制约。为了发挥出企业的规模相应，促进成本节约、提升运营效率、以及 改善或解决企业发展过程中的制约性问题，很多企业逐步进行非核心业务的剥离与整合工作，并逐步将主要精力与资 源等，投入到核心业务上去，这也使得财务共享模式应运而生。在此种全新的共享模式下，很多国际化的金融体系或 机构，均设立其针对财务共享模式的服务中心。而如何判断出财务共享模式的优势，以及其成熟的模式，对于现阶段 的企业成本管控而言，无异于是具有极大现实意义的。对此，本文首先阐述了财务共享模式下企业经营管理模式与传 
统模式下的不同; 然后本文结合前人的杰出研究成果与研究结论, 对企业管理成本进行了定义与详细归类, 将管理成 本分划为了组织内部成本、外部交易成本、机会成本、委托代理成本等三个大类并对各类管理成本的特性、核算模式 进行了介绍与归纳, 根据对管理成本性态和构成的描述, 本文结合财务共享模式的特点, 对管理成本在形成与核算两 个方面分别进行了控制优化研究。并由此总结出: 管理成本作为企业综合成本中重要的组成部分, 不仅需要进行财务 共享模式的实施, 更要不断完善管理成本的控制与构成的优化工作, 唯有如此, 才能促使企业在可持续发展的道路上 稳步前行。

关键词：财务共享模式，管理成本，性态及构成，形成与核算

\section{1. 引言}

近年来, 伴随着互联网技术与云端数据储存技术的快 速进步，企业的经营管理模式也在产生日新月异的变化。 虚拟空间超高的容纳性与连通性不断打破着时间阻隔与空 间阻隔对企业日常经营管理所带来的巨大影响, 规模越大, 发展区域越广的企业, 其消耗在沟通、管理之中的成本也 会越高。然而, 与之相反的是, 传统企业的管理效率与灵 活度却随着企业管理成本的增加而呈现出逐渐下降的趋势。 在不断发展的过程中, 企业也在谋求发展规模与管理效率 之间的平衡。财务共享模式便是在这样的背景下诞生的高 效财务管理经营模式。成本的良好管控, 是有效达成共享 服务的前提与基础。Deloitte国际咨询数据公司对《财富》 杂志内世界500强企业中的50家企业做出了细致的调查, 其 结果表明: 采用共享服务项目的投资回报率能够达到 $27 \%$, 人力成本可由此降低 $25 \%$ 左右。 ${ }^{1}$ 与此同时, 美国会计师管 理协会, 更是对全球 500 强企业中的 $1 / 5$ 企业, 做出了实施 共享服务模式与否, 以及所产生的差异性调查。其结果表 明: 采用共享服务的企业，不仅能够促使自身运营成本的 降低, 更能显著提升运营效率, 且经过精细化分析, 共享 模式所产生出的企业平均成本下降率高达 $81 \%$ 。 ${ }^{2}$ 同时, 由 于共享服务模式的应用, 更是能够为此类应用企业带来优 化资源配置, 以及强化核心业务等方面的优势。它通过云 端数据的储存与共享, 依托总部优先层级管理权限模式的 设置来达到简化、解放分公司内部财务机构并高效、统一 地管理、运作、划拨企业经营管理用财务资金的目的。然 而, 财务共享模式下的企业, 随着分公司财务机构撤销、 资金管理集权化等行为的开展，在后续的经营管理中也带 来了一些新的人力、物资以及管理上的问题。作为执行财 务共享模式进行经营管理的大型企业, 应当如何通过合理 的手段有效降低其不必要增加的管理成本, 已经成为了现 代企业经营管理中的重要研究问题。

\section{2. 财务共享模式的性质及特点}

\section{1. 财务共享模式下的企业管理模式}

由于财务管理模式下, 集团企业需要对分散在各个地 区、各个公司中的财务单元进行剥离与集中，对下属公司

1 Tim R. Tech report:shared services share where? [J]. CFO, 2000, 16(10): 101-106.

2 Denburgh E V, Denis C. Doing more with less [J]. Electric Perspectives, 2000, 25(1): 44-55
的财务工作精英人才也进行了调离, 这使得下属公司在其 管理链条上断开了一个环节, 这就好比原本各公司独立、 成体系的循环式内部管理模式, 现在变成了发散式的, 围 绕一个中心点进行延伸的放射管理模式（详见图1、2）。

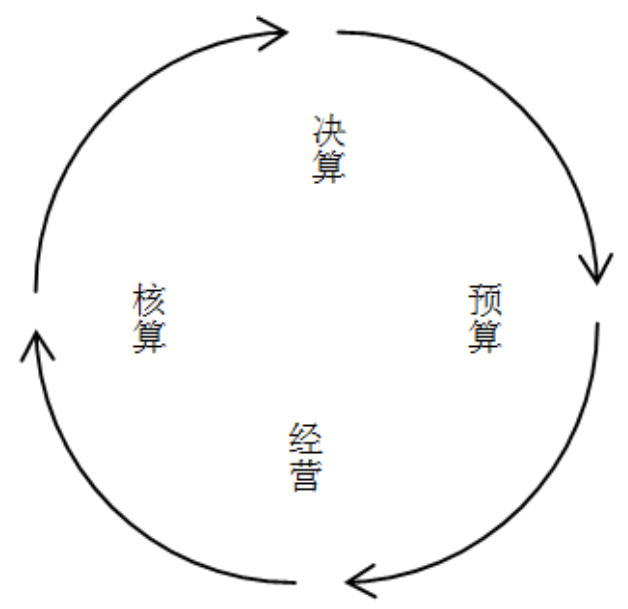

图1 传统模式下的企业管理。

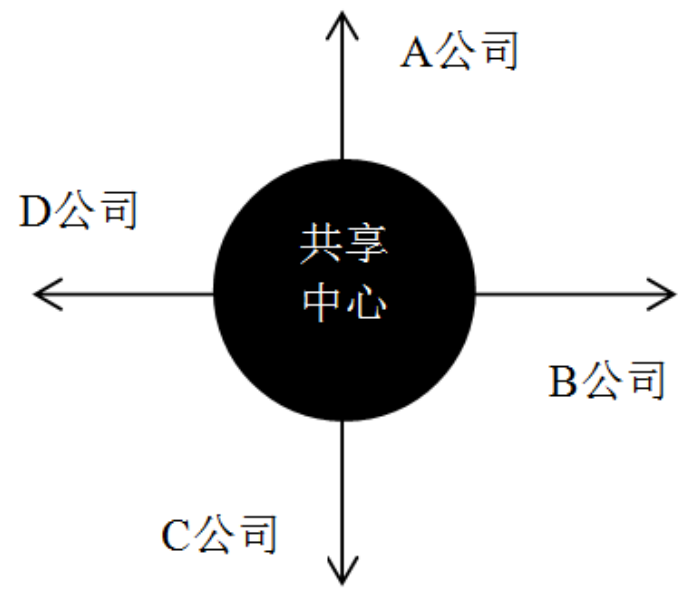

图2 财务共享模式下的企业管理。

从上图中我们可以看出, 随着财务共享中心的建立, 各个子公司的财务核算方式由传统的预算起, 决算终转化 为了围绕共享中心对各自所制定的预算而进行经营管理 的方式, 而最终的决算过程, 也会汇聚在财务共享中心得 以实现。在这样转独立为公共的过程中, 各子公司将需要 建立起一套新的办公系统及流程与财务共享中心之间进 行准确的接受与反馈。公司不再拥有独立的财务部门, 但 
会需要设立数据部门, 以接收、形成财务共享中心所提供 或需要的相关信息数据; 还会需要部分改变公司内部审计 的职能, 使得监管的重心由资金监管向责任监管进行转移 [1]。未来, 企业更多的将会投入成本使得财务共享中心的 工作能够得以维持并高效地在各下属公司之中进行推进 与介入, 单单靠软件系统无法完成这一灵活、多变的任务, 因此类似于财务共享专员的职位应运而生, 专门负责对财 务共享中心在集团企业内部的渗透与介入作用进行推进 与改善。同时, 相应地, 下属公司也会形成一套以数据人 员为核心的反馈系统, 以保证在配合财务共享目标下, 更 多地争取到统筹分配的企业资源 [2]。

\section{2. 财务共享模式下的企业办公模式}

财务共享中心建立后, 需要通过汇集的各项数据, 对 集团企业的各项业务进行综合、全面的评估，目的旨在于 帮助集团企业找出业绩更好、利润更高的企业业务, 资源 的集中调配也会根据财务共享中心的数据反映结果而赋 予不同的侧重方向[3]。这样的管理目的使得财务共享模式 下的集团企业将会采取比传统模式集团企业更加严厉的 资金、资源使用权限管理制度。集团企业下属子公司在无 权再自由调拨资金及资源, 因此各下属公司为了争取更多 的资源, 也会相应地采取一定的措施。公司在办公上将会 采取改变收入为导向的策略, 更多地关注盈利为导向策略。 简化各级机构, 简政放权。减少企业办公过程的中间成本, 减少各项业务手续, 更多地成本被用于生产技术的开发、 营销部门的建设 [4]。在这样的大环境下, 各下属子公司对 于营销部门以及销售人员的培养与重视也将投入更多的 关注。

\section{3. 财务共享模式下的企业财务活动模式}

在财务共享模式下, 企业减少了许多冗余的组织架构。 筹资方案需要向总部财务共享中心汇总进行申请审核, 由 财务共享中心结合企业资金使用情况对下属各子公司筹 资方案进行调整与批复。资金的筹集也通过总部财务共享 中心直接进行，筹集到的资金按批复情况分拨至各分公司。 各分数子公司的投资活动, 需要由总部财务共享中心统一 审批后划拨，并在后续过程中对资金的投资使用进行跟进 监测[5]。而企业生产、投资活动的收益，也将归入财务共 享中心统一核算, 为编制下年度预算报表、年度绩效考核、 收益分配、利润留存等提供依据。

\section{3. 企业管理成本的定义及类别}

\section{1. 企业管理成本的定义}

企业的管理成本, 由Kells (1962) 率先提出, 他认为 企业的管理成本包括了组织内部成本、外部交易成本、机 会成本、委托代理成本等四个重要方面组成。组织内部成 本包括企业形成主要组织架构所需要的构成成本以及维 持企业管理职能不断运作的维持成本, 如公式 (1) 所示。

$$
D=\Delta \mathrm{S}+\mathrm{F}_{\mathrm{i}}+\mathrm{p} \times(\mathrm{R}+\mathrm{I})
$$

其中, $\mathrm{D}$ 代表了组织内部成本之和, $\Delta \mathrm{S}$ 是从传统模式 运营专为财务共享中心模式时, 消耗的必要变动成本, $F_{i}$ 为下属分公司各自承担的固定成本。 $p \times(R+I)$ 代表了维持 职能的维持成本[6]。

外部交易成本包括企业拓展市场与规模所耗费的搜 寻成本，在交易过程中产生的诸如中介费用、评估费用等 相关的服务成本以及企业后续在经营合作中可能会面临 的履约成本, 如公式 (2) 所示。

$$
\gamma_{E}=\frac{v}{n-m} \times \frac{n}{360} \times \sum_{i=1}^{n}\left(X_{i}-\bar{X}\right)^{2}
$$

其中, $\gamma_{E}$ 是履约成本的衡量系数, $v$ 代表当时市场上 的实际折现率, $n$ 代表信用周期, $m$ 代表折扣期。 $\sum_{i=1}^{n}\left(X_{i}-\bar{X}\right)^{2}$ 在这里表示企业在不同资金集中享度下的 交易违约系数。

机会成本在此处并非传统意义上由于企业管理者在 进行决策时, 由于多项互斥方案无法同时满足而产生的放 弃成本, 而是指企业的管理机构工作与企业生产经营工作 之间的协调期所产生的不可避免成本, 这一成本主要是通 过计算组织资源利息支出的损失、市场及投资机遇由于管 理协调问题遭到耽误而造成的错失成本, 如公式 (3) 所 示。

$$
\mathrm{K}_{n}=\left(\eta_{1}+\cdots+\eta_{n}\right)(1+i)^{-n}-\sum_{z=1}^{m} d_{z}+\sum_{x=m+1}^{n-m} F(1+i)^{x}
$$

委托代理成本则是从委托代理理论出发所产生的可 量成本, 包括对管理的监管以及激励成本、承诺成本以及 企业的剩余损失[7] [8]。

在财务共享模式中, 企业由于取消了下属分公司中的 财务单元，对公司行政管理职能部门，以及公司财务权限 产生了巨大影响, 因此对于管理成本的构成与总额也会带 来较大的冲击。下面, 结合企业财务共享模式下的特点, 通过上述对管理成本的定义, 分类对财务共享模式下企业 管理成本所产生的变化进行分析与讨论。

\section{2 . 财务共享模式下的组织内部成本}

在财务共享模式下, 企业的组织架构由闭环式变为了 射线式，这使得集团企业总部的核心力凸显，企业内部控 制依赖于组织架构的变化而得到提升, 内部控制的员工依 赖度会适当下降 [9]。但是相应地, 企业组织架构的改变也 带来了一定的构成成本, 下属分公司财务单元的疏解, 财 务共享中心的建立, 中间配套设备的完备都需要投入一定 量的成本[10]。而由于财务共享中心的建立, 企业最初会 产生极高的运行成本, 这一运行成本的陡然增高, 是由于 企业的常规管理链条被打破, 一时无法很好适应新的管理 链条所造成的适应性成本。在一段时间之后, 运行成本会 有一定的下降, 但受限于组织架构的问题, 各下属公司于 总部财务共享在中心之间将会产生比以往更多的人员往 
来成本, 共享中心维持成本, 使得运行成本的总量较之财 务共享改革前, 还是会有一定量的升高。

\section{3. 财务共享模式下的外部交易成本}

对于外部交易成本中的服务成本而言么, 并不会产生 较大的变化。而搜寻成本与履约成本则会受到一定的影响。 由于财务核算的集中化管理, 原有的二级、三级财政结构, 统统变为了一级, 使得企业在项目及工程与财务的契合度 上会受到一定的影响[11]。财务共享中心地点位于总部, 面对的报表数据所反映的结果, 往往无法实际结合生产工 作经验进行判断, 因此容易出现误差, 这使得财务共享模 式可能导致集团企业在市场及项目拓展的决策上出现失 误，从而增加搜寻成本，而对于跨国、跨境的大型集团企 业而言, 财务共享模式下频繁的跨境资金转移, 将增加一 定的履约成本 $[12]$ 。

\section{4. 财务共享模式下的机会成本}

财务共享模式下, 由于各下属公司财务单元撤销, 部 分财务精英将被抽调进入财务共享中心任职，而余下的人 员除去被解聘的部分后, 还将有部分财务工作人员被分配 至其余不同行政岗位中任职，也有可能进入营销、生产部 门任职 [13]。由于这部分人员对于岗位的不熟悉, 将会需 要更多的时间予以适应, 这一过程中将会造成行政办公能 力以及管理效率的下降，同时企业财务共享模式下，对于 筹资、用资的审核与批复往往更加严密，而且考虑到资金 安全性问题, 部分财务共享的企业实际采用的是数据线上、 流程线下的财务管理模式, 使得其流程也往往更加复杂, 增加了一定的机会成本。

\section{4. 财务共享模式下管理成本的控制}

财务共享模式下, 由于企业的行政机构得到了简化, 财务管理更加紧凑与严密, 使得企业出现浪费成本、虚报 成本等行为的空间更低, 这不仅为企业管理成本的控制行 为拓展了空间，更为后续工作的开展奠定下坚实的基础 [14]。与此同时, 此种做法也减少了许多固定成本, 对于 企业管理效率的最终提高,以及财务成本的控制有许多的 益处。但是, 由于财务共享模式也存在一定的特殊性与局 限性, 再加上财务共享模式在我国企业中还处于起步阶段 以及我国国情、市场行情的影响, 采用这一模式的企业往 往管理成本会出现阶段性地升高, 下面, 本章将针对这一 问题, 探讨降低管理成本的途径。

\section{1. 加速线上管理的开发与建设}

在企业的管理成本中, 使用人力资源所产生的成本往 往会占很大一部分。而在财务共享模式下, 集团企业为了 更好地了解各下属公司的工作状况、经营业绩、管理状态, 会更多地加强分公司与总部之间的人员交流与流动; 分公 司由于失去了财务职能, 需要更多地依附于总部而存在, 因此也会更密切地出现与总部之间的人员流动 [15]。这就 使得运行成本开始增加。因此, 要解决这一问题, 首先需 要对现有的财务共享模式进行进一步的深入改革。不仅仅
做到财务数据的线上汇集，对于财务管理流程、审批过程、 业务办理等, 总部财务共享中心都需要能够尽可能地做到 实现与分公司之间的线上融接 [16] [17]。此外, 基于现阶 段计算机技术、网络技术、以及信息通信技术的高速发展, 公司总部也可由此利用手机移动终端, 构建起财务共享模 式下的企业财务信息管理平台。其中, 平台的整体权限由 公司总部财务部门负责人把控, 分公司可就财务问题与公 司总部进行手机移动终端的实时对接, 不仅增强了财务共 享目标的达成效果, 更为资金信息的实时流动与走向, 开 辟出透明化的窗口。通过此种方面, 既能显著改善分公司 与总部之间因人员流动与交流而生成的运行成本增加问 题, 又能促使公司内容形成基于互联网的财务共享模式网 络, 从而促使企业管理成本的措施更为便利, 也将极大的 提升财务工作的效率 [18]。

\section{2. 加强企业财务部门与管理层的综合素质}

企业财务部门工作人员的业务能力与意识, 是促进企 业管理成本得以有效控制的前提与基础。从企业长远发展 角度分析, 财务部门工作人员的综合素质提升, 是确保企 业管理成本降低的“安全门”, 更是促进企业核心竞争力显 著提升的重要组成部分[19]。对此, 企业应积极开展针对 财务部门工作人员的综合素质提升工作。一方面, 从培训 角度入手, 对企业内部财务部门的工作人员, 进行定期的 专业化知识与岗位技能培训, 除去财务日常工作中所涉及 到的专业知识与岗位技能外, 更要将与财务共享模式相关 的知识与技能做细致的分析与传授，促使财务部门工作人 员能够清晰认识到自身在工作中所存在的不足, 并加以改 正; 另一方面, 还应对财务部门的工作人员进行财务共享 意识的教育工作, 使其能够将财务共享意识融入到日常工 作之中, 如此便是从本质上转变了企业财务管理的传统模 式, 不仅会促使企业财务工作迈上崭新的台阶, 更会使财 务部门内部形成新意识+新老技能相融合的有力局面, 从 而为企业管理成本控制目标的有效达成, 做出进一步的推 动。

\section{3. 设立财务外勤部}

由于资源的集中调配，对于各下属公司的业务考核 也就显得更加重要, 不可避免地加剧了统一企业下公司 与公司之间的竞争。部分公司可能由于其生产经营项目 或公司本身所处地域环境及政策并不能很好地适应财务 共享的管理模式，业绩受到一定的打击。但这并不代表 公司的业务本身存在问题, 在如今的财务共享模式下, 盲目地通过看数据、看营收的方式来取舍公司业务, 容 易出现一定的纰漏, 也可能损失潜在的利润, 造成搜寻 成本被动上升 [20]。因此, 为了降低企业的搜寻成本, 总 部可以将各分公司中, 原属于财务单元内的剩余人员集 中起来, 设立财务外勤部, 财务外勤部将定期对各分属 公司进行实地考核, 从财务管控的角度, 对该分公司是 否适合如今的财务共享, 经营业务是否符合集团企业利 益进行评估。再通过评估与财务共享中心数据结合的方 式, 来更好地对集团企业业务的决策带来帮助, 从而提 高集团企业业务盈利的靶向引导, 降低搜寻成本。 


\section{5. 结论}

财务共享模式是现代企业生存发展过程中为追求效 率化管理，内部控制导向化管理而诞生的先进管理理念。 但是, 如果无法合理地将财务共享模式与集团企业自身的 业务特性，规模，经营区域等因素结合起来，将会使得其 应用效果适得其反。管理成本作为现代企业综合成本中越 来越重要的一部分, 直接反映了企业的管理水平与管理效 率。因此，合理地控制管理成本，优化管理成本构成，也 能更好地使得企业的财务共享管理方式得到贯彻与维持。 本文从线上管理、部门设立两个方面分析了财务共享模式 下对企业管理成本的优化控制方案，为企业财务共享模式 的探索以及管理成本控制问题的研究带来了新的思路。

\section{参考文献}

[1] 宋京津. 内部控制缺陷披露的成本与收益研究——基于关 系契约理论的分析 [J]. 财政监督，2015,(02):57-60。

[2] 王剑凌. 基于委托代理理论的国有企业代理成本分析 [J]. 当 代经理人, 2006,(07):43。

[3] 李寿喜. 代理成本与公司治理结构的逻辑关系 [J]. 李寿喜. 代理成本与公司治理结构的逻辑关系 [J]. 现代管理科学, 2008,(10):44-46+53。

[4] 俞红梅. 企业财务管理中的成本控制工作分析[J]. 俞红梅. 企业财务管理中的成本控制工作分析 [J]. 中国商贸, 2012,(09):91-92。

[5] 汪丹梅, 谭彦璇, 唐宝国. 从事后核算到过程控制的医院全 成本管理研究[J]. 会计之友, 2014,(04):54-58。

[6] 谢东明, 王平. 生态经济发展模式下我国企业环境成本的战 略控制研究[J]. 会计研究, 2013,(03):88-94+96。
[7] 许静. 管理会计在企业成本控制中的应用研究—— 以A公 司为例 $[J]$. 财会学习, 2015,(14):162-165。

[8] 王春梅, 周晖. 基于人力成本控制的人力资源管理模式构建 [J]. 改革与战略, 2011,27(11):53-55。

[9] 任洁. 我国企业集团财务共享服务中心的优化研究[D]. 陕 西科技大学，2015。

[10] 熊磊. 财务共享服务下管理会计信息化有效实施策略[J]. 会 计之友, 2015,(08):7-9。

[11] 唐勇. 财务共享服务下传统财务人员的转型 [J]. 财会月刊, 2015,(19):18-21。

[12] 王小琛. 集团企业财务共享服务中心的构建及实践研究[D]. 首都经济贸易大学，2016。

[13] 孙荣. 跨国公司财务共享中心的建设研究 [D]. 首都经济贸 易大学, 2016。

[14] 金灿灿, 王竹泉, 王海龙. 财务共享模式下企业营运资金管 理绩效研究——基于海尔集团2007～2014年的纵向案例 [J]. 财会通讯，2017,(02):98-103+129。

[15] 孙兰婷. 关于加强企业成本管理与控制的思考 [J]. 中国管理 信息化(会计版), 2007,(02):60-62。

[16] 门振洲. 基于财务共享服务模式下企业绩效管理问题思考 [J]. 中国经贸，2016(5):183-183。

[17] 万蓓.财务共享服务模式下企业绩效管理问题探讨[D].江西 财经大学,2010。

[18] 饶水林. 基于财务共享服务模式的企业财务管理研究 [D]. 湖南大学, 2011.(02):71-73。

[19] 倪敏. 基于财务共享服务模式的财务管理专业实践教学改 革研究[J]. 吉林工程技术师范学院学报, 2017,33(2):47-49。

[20] 王楠. 基于财务共享服务模式下电信行业本地网财务管理 问题的探讨 $[J]$. 财会学习, 2017(8):51-51。 